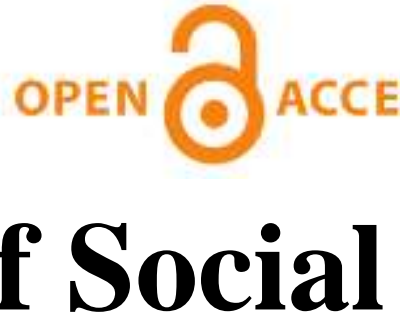 \\ International Journal of Soci
Sciences and Management
}

\section{A Rapid Publishing Journal}

ISSN 2091-2986

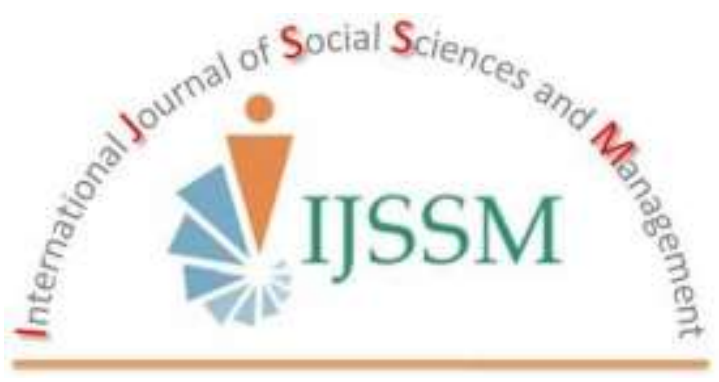

\section{Indexing and Abstracting}

CrossRef, Google Scholar, International Society of Universal Research in Sciences (EyeSource), Journal TOCs, New Jour, Scientific Indexing Services, InfoBase Index, Open Academic Journals Index (OAJI), Scholarsteer, Jour Informatics, Directory of Research Journals Indexing (DRJI), International Society for Research Activity (ISRA): Journal Impact Factor (JIF), Simon Fraser University Library, etc.

Vol- 3(1),January 2016 


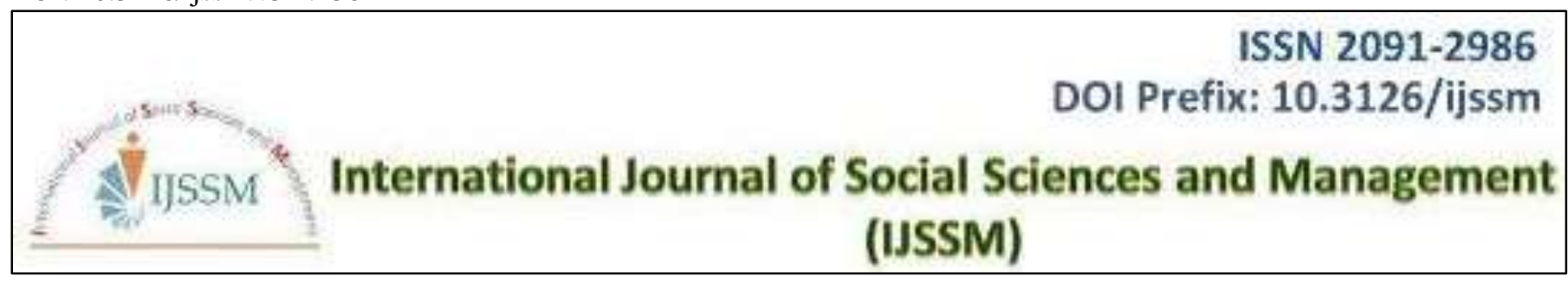

\title{
Research Article THE DIFFICULT ASSESSMENT OF THE FINANCIAL INCLUSION POLICIES IN INDIA
}

\author{
Aurélie Larquemin \\ Institute for financial Management and Research -IFMR LEAD, Chennai, India
}

Email: aurelie.larquemin@ifmr.ac.in

\begin{abstract}
Evidence of the importance of financial inclusion for economic growth and development are now well established and documented but little is known about the role institutions and policies can play and how institutional frameworks can support inclusive financial development. This paper is a case study on India, aiming to highlight the successes and difficulties encountered in the country financial development path. The results presented are based on an in-depth literature review and analysis of public secondary data. In the first section we discuss Indian initiatives for financial inclusion which started a decade ago, while in the second section we focus on more recent initiatives centered on digitization. Most of the oldest initiatives, through several changes and evolutions, have played a key role in expending financial inclusion in India, for instance the National Pension System or SHG groups. Public authorities are aware of the value of these schemes and have constantly tried to improve their features, expand their positive results and tackle identified issues. However they had too limited effects to allow the country to reach its goal towards financial inclusion. Moreover new technologies have appeared, opening new scope for financial inclusion, through innovative tools and schemes recently put in place by the public authorities. While we are lacking perspective to evaluate their effects, their preliminary results are encouraging and new schemes and regulations are being set up in this path.
\end{abstract}

Keywords: Financial inclusion; Economic growth; National Pension System; SGS

\section{Introduction}

Lack of knowledge on the impact of Institutions and their initiatives \& schemes on financial inclusion

Little is known about the reach of the financial sector and the policies expanding the inclusion.In a study in 2012, Allen et al. intended to establish the factors underpinning financial inclusion across individuals and countries. They found that greater ownership and use of accounts is associated with a better enabling environment for accessing financial services, such as lower account costs and greater proximity to financial intermediaries. Policies targeted to promote inclusion may be especially effective among those most likely to be excluded. Their results suggest that policies to reduce barriers to financial inclusion may expand the pool of eligible account users and encourage existing account holders to use their accounts with greater frequency and for the purpose of saving.

\section{Attribution of progress to one or more initiatives and policies is extremely difficult. In India few studies have established the efficiency of the implemented financial inclusion policies}

The penetration in rural areas has been associated with a reduction of poverty and a diversification out of agriculture (Burgess and Pande, 2003). In a paper in 2002
Banerjee and Duflo studied the Indian banking sector and showed that socially and even privately profitable lending opportunities remain unexploited in the current environment. In the first section we discuss decade-old initiatives for financial inclusion and their results, while in the second section we focus on more recent initiatives centered on digitization and how they could help India reach its financial inclusion goals.

\section{Results and perspectives on the decade old initiatives}

\section{National pension scheme NPS/ Swavalamban Scheme/Atal Pension Yojana}

As on March 31, 2014 the total number of subscribers was 6.5 million comprising of 1.4 million Central Government and Central Autonomous Bodies employees (accounting for about $21 \%$ of the total subscribers of NPS), about 2 million State Government and State autonomous bodies employees (31\%), 2.8 million Swavalamban subscribers (accounting for $43 \%$ of total number of subscribers) and $340,000(5 \%)$ subscribers from All Citizen variant.

The percentage of female subscribers has increased from $5.23 \%$ in FY 2008-09 to $39.1 \%$ in in FY 2013-14. The main jump has been registered after the introduction of the Swavalamban Scheme in 2010-11(73\% female subscribers). 
However the progress of the number of subscribers has been slow, especially over the first 3 years. One of the main reasons of this situation was the fact that there was no incentive for intermediaries to promote the NPS. For instance banks were only earning Rs. 20 per national pension system account, no matter the size of the investment.

The National Pension Scheme is a key tool for financial inclusion and Indian authorities are following carefully its performances and taking into account public and private stakeholders' comments in order to improve the scheme. Aware of its lack of attractiveness and awareness issues, the Government of India (GoI) have applied several changes over the past three years. They also give great importance to the reach of the scheme, especially among women and the poor. Hence the Swavalamban scheme was designed and later revised and replace by the Atal pension Yojana scheme in June 2015. For instance, to make the pension scheme more attractive, the government cocontributes $50 \%$ of a subscriber's contribution or Rs. 1,000 per annum, whichever is lower to each eligible subscriber account for a period of 5 years from 2015-16 to 2019-20.

It seems like the Indian authorities have not found yet the best combination of features for the national pension plans but keep working on their improvements. The impact of the latest reforms like the additional tax benefit should be closely monitored and more generally great attention should be given in developing an efficient and reactive monitoring system for these schemes.

\section{Swarnajayanti Gram SwarojgarYojana (SGSY)/ National Rural Livelihoods Mission (NRLM)}

Swarnajayanti Gram SwarojgarYojana is an employment program designed to encourage Below Poverty Line (BPL) family - swarojgari - to engage in income-generating activities by providing assistance through a combination of wages, technical capacity building and a package of financial assistance that includes institutional credit and subsidy. The target group of SGSY consists of small and marginal farmers, agricultural laborers, rural artisans and others whose annual family income is less than the BPL income level.

In 2010, the GoI restructured the SGSY program into the National Rural Livelihoods Mission, following recommendations from stakeholders' consultations. This evaluation revealed inadequate infrastructure and insufficient capacity building as main constraints. Most of the factors responsible for its poor performance relate to weaknesses in delivery systems (e.g. coverage of Swarozgaris, coverage of Minorities, slow disbursement of funds).

NRLM was launched in 12 states that account for $85 \%$ of the rural poor households in India. The GoI is investing US\$5.1 billion in NRLM over seven years and the World
Bank is committing US\$1 billion through its national rural livelihoods project (NRLP).

According to the GoI, some of the main features and change of NRLM include:

- Universal social mobilization through formation of SHGs under NRLM.

- To take the social mobilization process to the next stage of maturity SHG federations will be set up at the levels of villages, cluster of villages, blocks $\&$ districts.

- The goal of universal financial inclusion will be furthered by enabling SHGs to be linked to banks and to access credit from them.

The Indian authorities have been reactive and able to take into account results from the evaluations of national and international initiatives to revamp their scheme. By doing so they managed to attract funding from major international stakeholders like the World Bank.

\section{Self-Help Groups}

Evidence is still scarce regarding the assessment of SHG programs. NGO facilitators or banks implementing these programs do not feel the need to undertake impact monitoring and assessment unless directed to do so by donors or for studies undertaken by NABARD.

If assessment studies of SHG interventions have been implemented over the past years, many of them suffer from methodological or scope limitations. For many types of programs, attribution of impact is complicated. This is especially true for SHG type interventions as they are often implemented along with other economic and social development initiatives.

Notwithstanding the shortcomings of the assessment methodologies described above, these studies tend to show some positive effects of SHGs, as gathered by Nair and Tankha (2014):

- Helped promote the savings habit and increased the savings of SHG members;

- Improved their access to credit from mainstream financing agencies;

- Reduced the dependence on moneylenders through availability of credit at lower rates;

- Increased the use of loans for IGAs;

- Yielded moderate economic benefits in the form of higher household incomes and food security and in asset holdings;

- Contributed to increased household employment and poverty reduction;

- Resulted in empowerment benefits to women, who, through the experience of self-management of the SHG, acquired self-confidence and voice in the household and in the community; 
- Contrary to the vision of SHG development, SHG membership is quite broad-based and members do not generally constitute the poorest;

- There is greater evidence of social empowerment rather than significant and consistent economic impact, except in the case of families involved in small businesses.

Given the diversity of models, purposes, and stakeholders involved, it is difficult to clearly identify the elements of 'good practice' among SHGs or any kind of minimum requirements to obtain the positive effects listed above. Comprehensive impact monitoring exercises have to be conducted to confirm these findings.

Over the past 20 years of SHG-Bank Linkage Program implementation, literature and stakeholders have identified several factors affecting the positive effect of the program. This assessment led to the conception of SHG-2 Guidelines.

According to a Round table organized by ACCESS Development on the next phase of development of the SHG model in September 2011 and recent literature, among those issues could be found:

- The fact that only a third of SHGs nationwide were considered of good quality by practitioners and researchers, questioning the infrastructure built and investments made;

- The dependence of SHG on NGOs or NBFCMFIs for loans;

- The limited credit absorption capacity of SHG after two or three loan cycles;

- The need for convergence between the SGSY/NRLM and SHG-BLP programs;

- The SHGs access to larger loans, too large for the principle of mutual help and collective liability to sustain;

- The Banks reluctance to bear the costs of the infrastructure for financial services that needs to be built for lending through SHGs;

- The lack of innovative products on offer to SHGs and their failure to respond to the financial needs, particularly in regards to savings products and regarding new technologies;

- The reluctance of banks to lend to SHG federations and this channel not being able to develop;

- The credit-focused orientation of SHG-BLP, the savings function had not been adequately developed;

- The need for capacity building of SHGs and SHG-based institutions was required, support is not only needed until SHGs were 'linked' but thereafter too.
Comprehensive impact monitoring exercises in the near future would allow measuring the impact of the new SHG2 Guidelines, if they are well implemented, and if they are sufficient to resolve the identified weaknesses of the SHGBLP model.

\section{Business Correspondent Model}

Recognizing that financial inclusion progress were slower than expected, RBI introduced a regulation in 2006 allowing banks to use the services of third-party, non-bank agents to extend their services right to people's doorsteps. Since its inception the $\mathrm{BC}$ model has become more diverse and complex and with this evolution issues have arisen. Today individual BCs stand alongside corporate BCs, which were originally technology providers. The list of entities allowed acting as business correspondents for banks keep being enlarged due to the unsatisfactory evolution of the Indian financial inclusion indicators. However most of these models present issues, have disappointing performance regarding financial inclusion and reach sustainability with difficulty.

Issues like the unviability of the cost structure and the lack of commitment of banks are well known to the stakeholders. Most banks fail to see the provision of adapted financial services to the financially-excluded as a viable business activity. Therefore they were unwilling to invest resources in this new market and remained with very small financial inclusion portfolios.

An important study on the impact of $\mathrm{BC}$ on financial inclusion are the national surveys of BCs implemented by CGAP and the College of Agricultural Banking (CAB). Their first survey was undertaken in March-May 2012 and covered 1030 Customer Service Providers (CSP) in the 11 states where financial inclusion was the most advanced.

- Among the contacted CSPs, 25\% had been experiencing connectivity issues affecting their ability to make transactions and were dormant;

- $29 \%$ of CSPs offered only one product category; $23 \%$ two products and $16 \%$ only No-Frill accounts;

- Median number of transactions was 14 per day;

- Over 58\% reported earning less than Rs. 3000 per month, and $21 \%$ less than Rs. 1000 . The median monthly income was Rs. 2735;

- Marked differences between rural and urban CSPs, the first ones improving the most difficulties.

These results clearly show the limitations of the model with low level of client use, low level of agent compensation and strong evidence of sustainability, even viability problems.

The low level of client use can be partially explained by the lack of trust of account holders in BCs and their lack of awareness. These phenomena were put in evidence by the Financial Inclusion Insights (FII) India Tracker Survey 
implemented by InterMedia in 2014, showing that only $3 \%$ of accounts holders surveyed fully trusted BCs while $48 \%$ were not properly aware of these services.

Several studies were conducted by stakeholders (Grameen Bank and Enclude, Microsave and NABARD)showing that BCs models were more stable and viable when a wider mix of products was enabled. Issues most commonly identified are lack of appropriate products, a need to focus on customer awareness, streamlining back office operations, and defining ownership.

The Indian institutions are aware of the limitations of the BC model and its difficulties. Many of their latest initiatives aim to resolve some of the issues presented above. For instance RBI has removed restrictions limiting one agent to transact on behalf of only one specific bank. Customers can now transact at customer service points (CSP) of one bank even if their accounts are held at another bank. This has allowed the entire banking system to be more efficient by sharing customer service points and lowering overall costs. However past efforts have not been sufficient and proven solutions, efficient and sustainable BC models are yet to be established. The latest initiatives in this domain and their impact need to be closely monitored and measured. More interoperability and digitalization of the financial inclusion framework, and viable business cases are essential for the sustainability of the BC model, particularly in remote areas.

\section{Digitalization and financial inclusion: a critical path to organize}

India has ambitious goals to deliver electronic welfare payments, banking services, and digital local Government services to each of its 638,000 villages. Many challenges remain on the road to a cash-free economy as about $60 \%$ of the country's 1.2 billion live in rural areas and many lack connectivity and infrastructure. Opportunities but also challenges erupt from the fact that India has two major initiatives in progress for digitalization and financial inclusion: the PMJDY program and the Direct Benefit Transfer (DBT) Initiatives. As highlighted by CGAP (2015) it will be crucial that these two initiatives are built in synergy, to enable a viable digital channel that can provide all financial services to the rural customer.

\section{Current infrastructure: components, results and impediments}

\section{Electronic payments}

Following the Task Force on the Aadhaar-Enabled Unified Payment Infrastructure report and recommendations to reach a cash-less economy, big investments and developments were made in electronic transfers. The number of transactions under retail electronic payments rose from 167 million to 2,268 million while the volume of transactions grew from Rs. 500 billion to Rs. 50,000 billion over the past decade (2004-2014). However the average volume of transactions remains stagnant over the past five years.

\section{Aadhaar - Unique Identification Authority in India (UIDAI)}

Up to March 2015, Unique Identification Authority of India (UIDAI) has generated 818 million Aadhaar numbers, covering $67 \%$ of the population in the country (considering the population data from the Census 2011). Enrolment statistics indicate that about $80 \%$ of residents have given their consent for opening bank accounts during enrolment. RBI made this possible by allowing Aadhaar numbers to be accepted as equivalent to banks' Know Your Customer (KYC) norms, and later by accepting Aadhaar as an e-KYC identifier for financial transfers in March 2014. The UIDAI is partnering with financial institutions to both augment enrolments through them and to provide bank accounts to residents during Aadhaar enrolment. This facilitates the KYC process for the customer and drastically reduces the cost of customer acquisition for the banks.

The UIDAI is changing the perspective on financial inclusion, making it conceivable to have full coverage in a very near future. The system utility needs however to be maximized. It could for instance enable easy merging of customer data across banks and improve the efficiency of the Credit Bureau system in place in the country. To reach this, Aadhaar e-KYC access should be accessible in all banks. The UIDAI can also facilitate the disbursement of government subsidies and is a key tool for the planned coverage extension of the DBT scheme. However issues remain that will need to be considered, like the viability of the system for the last mile delivery agents in charge of the Aadhaar enrolment.

\section{RuPay Cards}

According to data from the Ministry of Finance 26.8 million RuPay Card had been allocated on October $15^{\text {th }}$ 2014, 25,8 million by public banks, 726,000 by rural banks and 281,000 by private banks. Out of the 44,6 million debit cards in circulation, it represents $58 \%$ (and 39.9\% out of debit and credit cards (20 million) in circulation). And, this number has been achieved in a relatively short time. The Jan DhanYojana has given RuPay a big boost as every account-holder is getting the RuPay card. The direct benefits transfer scheme has also helped in making the RuPay cards active.

Inactivity of the cards and accounts linked to them is an important issue. Indian authorities are counting on schemes like DBT to lower the level of inactive accounts. NABARD has also taken the initiative to promote the use of the RuPayKisan Cards among the rural population by helping rural banks and cooperatives implement core banking solutions and by facilitating the installation of micro ATMs and PoS. 


\section{ATM/Kiosk banking model}

The number of ATM operating in India has increased massively over the past few years. The total number of ATMs of public sector banks on March $31^{\text {st }} 2015$ was 122,895 . However most of these ATM are located in urban areas. As of March 2014, only 14\% of the ATM were located in rural areas. Two-third of the ATMs installed between September 2012 and March 2014 are located in such areas.

Banks are not finding the ATM technology viable for rural areas. As shown by the InterMedia FII India Survey, only $28 \%$ of Indian bank customers trust ATMs for their financial operations. Banks and financial institutions would benefit studying and improving their ATM model in rural areas. Making these machines deliver smaller notes could make them more attractive in rural areas and launching training and education programs could be a valuable tool to improve customer's trust.

Improvements of the model have already been implemented, with the creation of the kiosk banking model. With this model, a retailer can open a BSBDA account for a customer by recording fingerprint details and taking a photograph of the customer. These details, along with other documents, are forwarded to the affiliated bank branch to carry out the know-your-customer process. Once the account is up, a customer can withdraw, deposit or remit a maximum of Rs. 10,000 per day through the internet-enabled kiosk branch. This new option takes into account the fact that still an important part of the rural population is illiterate; hence having a retailer taking part in the client banking operations process can help deal with the usability issue.

\section{Mobile banking}

The first set of mobile banking guidelines were issued by RBI in October 2008 allowing banks to facilitate fund transfers through mobile phones from one bank account to another, both for personal remittances and purchase of goods and services. Real time inter-bank mobile banking payment has been facilitated through the setting up of the Interbank Mobile Payment Services now called Immediate Payments Service (IMPS). The IMPS enables real time transfer of funds between bank accounts and provides a centralized interbank settlement service for mobile banking transactions. As on $31^{\text {st }}$ May 2014, 86 banks, including 10 RRBs and 19 commercial Banks, had been permitted to launch mobile banking services.

Intermedia conducted the Financial Inclusion Insights (FII) Tracker Survey in 2014 to track access to and demand for financial services generally; measure adoption and use of digital financial services (DFS) among key target groups (females, Below Poverty Line households, rural, unbanked, etc.); identify drivers and barriers to further adoption of DFS; and evaluate the agent experience and the performance of mobile money agents.

Regarding mobile banking, the study highlighted that:
- Mobile phone access is above $75 \%$ across all states of India, with the exception of Assam, Orissa and Madhya Pradesh where access is lowest, between 60 and $70 \%$;

- Mobile phone access is high, overall, but women are less than half as likely as men to own their phones (68\% of men and only $31 \%$ of women) ;

- Smartphone penetration is low, most respondents have access to a basic mobile handset, with urban men and young people (15-24) are most likely to have access to a smartphone.

- Based on both spontaneous and prompted recall, only $6 \%$ of respondents are aware of any mobile money products. Awareness is significantly higher among those above the poverty line and those who have access to a mobile phone and SIM card.

- Mobile money users tend to use the service infrequently, mostly for sending money. $25.2 \%$ of the respondents only hold an active bank account (while $74.7 \%$ of the respondents do not have an active bank account nor mobile money account).

In October 2013 RBI had set up a "Technical Committee on Mobile Banking" to study the challenges faced by the banks in providing mobile banking to customers and to examine the options and alternatives for expanding the reach of mobile banking in the country. Their recommendatiosn were later included by RBI in its revised operative guidelines for banks - Mobile Banking Transactions in India - published in December 2014. They mention the necessity: (i) for easier registration; (ii) for standardization in procedures related to on-boarding new customers and authentification, (iii) for banks to offer awareness and customer education programs; and (iv) for a list of channels/methods that banks should consider adopting to improve their mobile banking activities. The impact of these new guidelines is yet to be measured.

\section{Global results, challenges and way forward}

2014 has witnessed some major achievements towards a cash-free economy with policies being set-up to create new actors like payments banks and small finance banks, the push given to the PMJDY, and the recognition of Aadhaar as an e-KYC identifier for financial transfers. Another key progress is the enhancement of the Direct Benefits Transfer coverage with the inclusion of 35 major national schemes. However the road is still long until reaching complete financial inclusion and full digitalization of the financial services.

\section{Digital financial inclusion status}

The InterMedia India FII Tracker Survey implemented in 2014 study the use of digital financial services by customers. 
Respondents still have a strong preference for cash transactions. Even considering the drawbacks (like increased theft risk or higher temptation to spend), cashis still considered as easier to access and to handle transactions with. Bank transfers are only preferred for large transactions, by $59 \%$ of respondents, while for small to medium operations $82 \%$ prefer cash. Wealthier respondents are six times more likely to receive their wages via a direct deposit to their bank than those below the poverty line. Non-cash payment delivery methods are also more common in urban centers. The study also reveals that bank branch is still the preferred place for banking operations $(71 \%)$ while internet banking is only the preferred mode of accessing banking services by $0.3 \%$ customers.

Intermedia also implemented a qualitative study of digitized Government payments with government-payment beneficiaries across four districts in the state of Maharashtra conducted in December 2013, focusing on the potential for digital government payments to expand financial inclusion.

Findings from this qualitative study include:

- Beneficiaries see advantages of using the DBT method to receive payments into their bank accounts, including fewer delays and full receipt of payment. But the process of switching to DBT needs to be easier and more efficient.

- Benefit payments are small, sometimes infrequent, and do not currently help to expand digital transactions.

- Beneficiaries have to be incentivized to reduce payment cash-outs and to use linked digital products, especially for older and rural beneficiaries. Banks also need incentives to design and market products to DBT account holders, and incentives for agent and $\mathrm{BC}$ networks need to be revised.

Another study from CGAP in Andhra Pradesh reached to the similar results. It was implemented in 2012 and 2013 to find out why the 16 million government-to-person (G2P) accounts are not being used except for one transaction per month to disburse the G2P payment. Several barriers were identified:

- Lack of awareness among recipients;

- Technology solutions not letting enable customers to use the account at any other time or for any other purpose other than to receive a benefit from a particular agent;

- High costs;

- Lack of incentives for banks to deliver financial products.

\section{Challenges and way forward}

The JanDhanYojana scheme, and the Direct Benefit Transfers (DBT scheme) have the same objective: improving the poor's livelihood and Indian growth and development. Their infrastructures are intertwined, they use some of each other components at one point or another, but they are not yet fully integrated. This situation generates barriers to the full success of these policies that need to be resolved. To maximize the impact of both schemes, the whole operating channel needs to be viable and sustainable. This implies revising and clarifying the business case and service charges under which the agents covering the last mile delivery are operating on, like business correspondents, rural banks and future agents (like small finance banks and payment banks). CGAP research showed that the State Government of Andhra Pradesh paid banks Rs. 2 for every Rs. 100 disbursed, when it costs the bank between Rs. 2.6 and Rs. 2.9. Out of the Rs. 2 that banks get, Rs. 1.75 get passed on to the banking correspondent company that looks after agent aggregation, technology, and cash management. Moreover at the policy level, the terms and conditions for financial service providers to operate as $\mathrm{G} 2 \mathrm{P}$ providers are currently unclear and vary from state to state, which partly explained the lack of commitment of banks for these services.

In the light of many studies' results, these troubles with the access to these schemes come together with an important lack of awareness and financial literacy. Therefore the maximization of their impact will also require strong and organized efforts in this area, so usage of accounts and level of transactions increase - two essential aspects of financial inclusion - and both schemes reach the necessary scale for sustainability.

The interoperability of the infrastructures and the digitalization are key elements for the success of the PMJDY/DBT initiatives and improvements in this area have already generated great progress as detailed earlier. More remain to be clarified, particularly regarding the costs involved in the necessary extension of digitalized retail payment infrastructure (e.g. installation of more micro ATMs, biometric authentication systems etc. at BC and retail merchant points), who will be bearing them and to what extent. Connectivity difficulties are highlighted in many reports, hence solutions need to be found and implemented with telecom companies to ensure full national telecom coverage and broadband access to $\mathrm{BC}$ and retail points. In the meantime and as suggested by CGAP (2015) manual solutions should be foreseen.

Synergies among the infrastructure components and stakeholders remain to be fully exploited. With digitalization are coming new partnership opportunities among Indian public institutions, credit, savings and insurance providers and telecom companies (for example multi-service products, data/information sharing 
possibilities). The next years will have to be dedicated to building a robust digital infrastructure that (i) can reach every remote village in India; (ii) is transparent, eliminates leakage and corruption (iii) allow providing a range of services, including bundle products; and (iv) combines enabling infrastructure, sustainable business case, and customer centricity.

To do so many observers have highlighted the necessity for policy makers designing financial inclusion, G2P, and electronic governance to have a regular dialogue at all levels (national, state-level, etc.) and to set up a permanent cooperation structure like multi-disciplinary agencies at the state level overseeing the policies implementation. It seems to be the idea behind the latest RBI decision to set up a committee to define a medium-term (5 years) measurable action plan for financial inclusion.

\section{Conclusion}

Despite conclusive proof of positive outcomes of older and more recent initiatives towards financial inclusion, Indian authorities and financial inclusion actors lack measurement and knowledge of the outcomes and impact of these past and actual initiatives. It is commonly acknowledge than the shift in the financial inclusion efforts, as illustrated in the Pradhan Mantri JanDhanYojana (PMJDY) policies and recent schemes like the DBT program, are a move in the right direction. However evidence are lacking to establish correlation or causality between specific policies and the financial inclusion situation in India, and to design the next phases of the financial inclusion efforts. An ambitious program of evaluation of these policies would highlight success and failures and help shape the next steps of financial inclusion support.

\section{References}

Allen F,Demirgüç-Kunt A, Klapper L and Martinez Peria MS (2012) The Foundations of Financial Inclusion: Understanding Ownership and Use of Formal Accounts. Policy ResearchWorking Paper 6290

Banerjee A and Duflo E (2002) Do Firms Want to Borrow more? Testing Credit Constraints Using a Directed Lending Program. BREAD working paper number 2003-005.

Burgess R andPande R (2003) Do Rural Banks Matter? Evidence from the Indian Social Banking Experiment. MIMEO Columbia University, March 2003.

Garg S and Agarwal P (2014) Financial Inclusion in India - a Review of Initiatives and Achievements", Journal of Business and Management (IOSR-JBM) Vol.16 Issue 6, June 2014

Intermedia (2014) Financial services use and emerging digital pathways, Highlights from the FII Tracker Survey and the Digitized Government Payments Qualitative Study. Financial Inclusion Insights

Nair T and Tankha A (2014) Inclusive Finance India Report 2014, Access Publication

Singh A Singh L and Sadana M (2015) PMJDY: Improved Financial Inclusion, But Roadblocks Remain. CGAP 2015: The year of Indian Financial Inclusion Series 